International Journal of English Literature and Social Sciences
Vol-6, Issue-4; Jul-Aug, 2021

Peer-Reviewed Journal

\title{
Mindfulness, Self-compassion and Resilience among Fifth Graders at Al Makassed Dawha School in Lebanon
}

\author{
Raymond Akiki ${ }^{1}$, Norah Dahdouli ${ }^{2}$, Ossama Dimassi ${ }^{1 *}$
}

\author{
${ }^{1}$ American University of Europe, Northern Macedonia \\ ${ }^{2}$ Department of Education, Lebanese International University, Lebanon \\ ${ }^{1}$ American University of Europe, Northern Macedonia \\ *Corresponding Author
}

Received: 30 Jun 2021; Received in revised form: 25 Jul 2021; Accepted: 05 Aug 2021; Available online: 13 Aug 2021 C2021 The Author(s). Published by Infogain Publication. This is an open access article under the CC BY license (https://creativecommons.org/licenses/by/4.0/).

\begin{abstract}
Elementary school students in Lebanon are subjected to various adversities and difficulties. Promoting mindfulness and self-compassion is important in affecting their resilience so that they can overcome these adversities. This study aims at assessing the mindfulness, self-compassion and resilience among fifth graders at Al Makassed Dawha School in Lebanon. To achieve this aim, fifty students were involved in this study. The extent to which students were originally mindful, self-compassionate, and resilient was measured using different surveys. The collected data were analyzed using SPSS version 25.0, and the relation between these variables was statistically tested using Chi-square and Kendall tests. The impact of self-compassion and mindfulness on resilience was deduced from students' reflection on the implementation of the Mindful Self-Compassion Program (MSC). The results showed that the majority of the enrolled fifth graders in this study had good standing self-compassion and resilience, but they had low levels of mindfulness. Mindfulness and self-compassion are found to be positively and significantly correlated with each other. The MSC was partially implemented and the highest good standing percent (90\%) was recorded in the self compassion test, while the lowest students being in the good standing category was in the mindfulness test results (46\%). As for the number in the good standing category, it mounted up to $70 \%$. The research recommends the need for following up the development programs of mindfulness, self-compassion, and resilience within the school context and promoting awareness about their importance.
\end{abstract}

Keywords_Fifth-graders, Mindfulness, Resilience, Self-Compassion,

\section{INTRODUCTION}

Living in a world dominated by a rapid lifestyle has exposed our children to often experience anxiety and depression, which highly contributes to bullying, low selfesteem, and sometimes isolation. However, when they learn how to stay mindful through their struggles, and how to respond toward themselves with compassion and kindness, things will start to change and will generate into greater happiness and motivation, as well as better relationships and a healthy well-being. As a result, children will have the resilience needed to cope with stressful life events. Children can also learn to embrace their insecurities and flaws, despite the challenges they face, they can shield themselves with the needed strength to strive [1].

Mindfulness has emerged from focusing on its benefits for physical health and pain management to include cognitive and emotional processes, which is aimed by improving child's emotional regulation that helps to alleviate stress, and leading into a peaceful mind state and mood [2]. When mindfulness interventions are properly applied in schools, children's anxiety, depression and self-hostility are mitigated, and therefore long-term coping with stressful 
situations is enhanced. This is utterly linked to increased resilience [3].

Teaching children self-compassion will make them intrinsically value themselves positively even at their worst failures. Thus, enduring low self-esteem, or isolation won't be an option for children who are empowered with self-compassion and inner strength. This act will reflect on children's behavior, and aid in reducing bullying towards others fostering a healthier community [4].

Implementing mindfulness and self-compassion programs in schools' curriculum is a fundamental process to build a resilient child who can smoothly adapt and regulate his/her emotions when facing life stresses [5]. Fewer behavioral issues, academic success, enhanced physical and emotional well-being, and improved relationships are the harvest of implementing an effective emotional development program that is crucial in the $21^{\text {st }}$ century [6]. Unfortunately, only one school in Lebanon has invested time and money to give life to this integral program, the "East Wood International School" in Beirut, which declares the pride to implement the "Mindfulness Program" for students, K-12, throughout the academic year. They clarify the importance of equipping students with the powerful tools for children's mind, spirit and body offered by this program to help them develop holistically [7].

Maalouf et al. found out that $26.1 \%$ of Lebanese adolescents were diagnosed with psychiatric disorders, like anxiety, attention deficit hyperactivity, disruptive behavior, and mood disorders [8]. Parental separation and unhealthy peer relationships were the main causes of these results. Khamis et al. [9] also discovered that suicide was attempted by $15 \%$ of the adolescents due to the uneasy circumstances, and lack of coping and dealing strategies with life difficulties. Unfortunately, schools in Lebanon are in short of proper preparation for youth to overcome their problems by teaching them mindfulness and selfcompassion skills as tools to build their resilience. Most of the Lebanese schools are in need for guidance and counseling specialists whom would highly help solve this problem [10].

\section{CURRENT STUDY}

The purpose of this study is to examine the approach of Mindful Self-Compassion program and its impact on boosting fifth graders' resilience at Al Maksassed Dawha School in Lebanon. The research indicates to what extent are these children mindful, self-compassionate, and resilient. This study also aims to insight into the fundamental relationships between mindfulness, selfcompassion and resilience through correlational analyses.
In addition, it highlights how mindfulness and selfcompassion interventions can impact children's resilience. Therefore, it focuses ultimately on the strengths as well as the component factors that uniquely shape this program and promotes a psychological well-being that leads into children's emotional growth.

\section{METHODOLOGY}

\subsection{Definitions}

Mindfulness: Paying attention; on purpose, in the present moment, and non-judgmentally [11].

Self-Compassion: Responding by being supportive and understanding towards yourself when going through hardships and difficulties, the way you would with a dear friend [12].

Resilience: It's an ineffable quality that helps people adapt well in life when facing significant stresses, challenges, tragedies and failures. Resilience is finding a successful way to rise from ashes [13].

Self-kindness: Self-kindness is treating oneself kindly even when failing or suffering. It's the action of being tolerant and soothing toward oneself in the most inadequate times by supporting and taking care of oneself [14].

Self-judgment: Forming negative opinions and acting on judging oneself is known as self-judgement. Hence, being too hard on oneself with unkind thoughts and feelings results in judging oneself [15] [16].

Common humanity: It's the recognition of not being the only person who is suffering and feeling pain for its human's nature all around the world [17].

Emotional well-being: Emotional well-being is the absence of negative affect and the presence of positive affect. It is the general appreciation and satisfaction of life [18].

\subsection{Research Design}

For this research, an exploratory sequential mixed methods design has been chosen as a collecting data process. Exploratory sequential mixed methods research has been defined as a representation that includes the approaches of both, quantitative and qualitative; collecting, analyzing, and interpreting data in a certain sequence in the same study that investigates an underlying phenomenon [19]. The researcher starts by collecting qualitative data to be analyzed in the first phase which develops the research questions for the second phase "quantitative", where data is collected through a survey, or questionnaire, or other valid form [20].

\subsection{Procedure}


In an elementary private Lebanese school in Saida, Al Makassed Dawha School, all fifth grade respondents were subjected to three different surveys to scale their level of mindfulness, self-compassion, and resilience. The 50 respondents were fifth graders - elementary students both young males and females of 10-11 years of age range.

The MSC Program was introduced as a new unit by the teacher (researcher) where 3 surveys have been distributed, one at a time, to rate the students' mindfulness, selfcompassion, and resilience. Then, they were introduced to different techniques that aid in enhancing these three components. The teacher followed different strategies and demonstrated a bundle of valid tools to help students comprehend the importance of this program, as well as to adopt its mechanisms. The program's implementation took three intermittent months.

Triangulation method was applied to analyze the findings and to come up with the final results. The students were asked to fill in three surveys about mindfulness, selfcompassion and resilience and to add their reflection by the end of the unit as an assessing tool. The school's counselor as well as the researcher monitored students' progress. By the end of the unit, the counselor was interviewed and reported her response toward this program along with its impact on the fifth grade students.

\subsection{Data Collection}

Based on the approval of the Institutional Review Board -IBR-, the researcher introduced to Al Makassed Dawha School's principal the MSCP -Mindful Self-Compassion Program- and acknowledged her of all its objectives and procedure.

\subsubsection{Child and Adolescent Mindfulness Scaled Items}

The first component tested was mindfulness following the "Child and Adolescent Mindfulness Measure" scale, which measures how mindful the children are towards their own feelings as well as their capacity of focusing at the moment they are in without destruction. The Likert scale conducts of 10 items that uses a 4 point rating from 0 "Never True" to 4 "Always True". Certain studies that aimed to assess the internal consistency of the CAMM have been conducted to prove its reliability and validity [21]. The scaled items are:

Item 1: I get upset with myself for having feelings that don't make sense.

Item 2: At school, I walk from class to class without noticing what I'm doing.

Item 3: I keep myself busy so I don't notice my thoughts or feelings.
Item 4: I tell myself that I shouldn't feel the way I'm feeling.

Item 5: I push away thoughts that I don't like.

Item 6: It's hard for me to pay attention to only one thing at a time.

Item 7: I get upset with myself for having certain thoughts.

Item 8: I think about things that have happened in the past instead of what's happening right now.

Item 9: I think that some of my feelings are bad and that I shouldn't have them.

Item 10: I stop myself from having feelings that I don't like.

\subsubsection{Self-Compassion Scale Scaled Items}

Self-compassion was the second component to be tested using the "Self-compassion Scale" [22]. This Likert scale contains 12 items that measure self-kindness, selfjudgement, common humanity, isolation, mindfulness, and over-identification, and it uses a 5-point rating from 1 "Almost Never" to 5 "Almost Always". Neff states that this scale has consistent reliability and concurrent validity on both genders. The scaled items are:

Item 1: When I fail in something important for me I become consumed in feelings of inadequacy.

Item 2: I try to be understanding and patient towards those aspects of my personality that I do not like

Item 3: When something painful happens I try to make a balanced view of the situation

Item 4: When I am feeling down, I tend to feel that all other people are probably happier than I am.

Item 5: I try to see my failings as part of my human condition

Item 6: When I am going through a very hard time, I give myself the caring and tenderness I need.

Item 7: When something upsets me, I try to keep my feelings at balance.

Item 8: When I fail in something that is important for me, I tend to feel. Alone in my failure.

Item 9: When I am feeling down I tend to obsess and fixate on everything that is wrong.

Item 10: When I feel inadequate in some way, I try to remind myself that feelings of inadequacy is shared by most people.

Item 11: I am disapproving and judgmental about my own flows and inadequacies.

Item 12: I am intolerant and impatient towards those aspects of my personality that I do not like. 


\subsubsection{Resilience}

As for the last component, it was applied through a simplified approach called "The Resiliency Quiz" [23]. The scale of this Likert consists of 14 items/statements that measure an individual's capacity of resilience. A 5-point rating is used in this scale from 1 (Very Little) to 5 (Very Strong). Al Siebert declares the validity of this quiz to help children and adolescents assess their resilience, and then strengthen it throughout their lives.

Data analysis was based on the total number of check marks on lines A and B. If there are 4-7 check marks on line $A$, it can be concluded that the participant has good resilience. Also, this means that this participant tends to recover from stressful events more easily. On the other hand, if a participant has $0-3$ checks on line $A$, then $s /$ he may have poor resilience "Table 1".

Table 1 Resilience Quiz

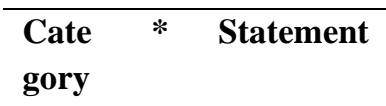

\begin{tabular}{|c|c|c|}
\hline \multirow[t]{2}{*}{1} & & $\begin{array}{l}\text { I am aware when things are going badly in } \\
\text { my relationships. }\end{array}$ \\
\hline & B. & $\begin{array}{l}\text { When there are relationships issues, people } \\
\text { rarely ask for my advice. }\end{array}$ \\
\hline \multirow[t]{2}{*}{2} & A. & I embrace individuality. \\
\hline & B. & I tend to be influenced by friends. \\
\hline \multirow[t]{2}{*}{3} & A. & I enjoy listening to and meeting new people. \\
\hline & B. & $\begin{array}{l}\text { When faced with my own problems, I often } \\
\text { feel like I have no one to get to. }\end{array}$ \\
\hline
\end{tabular}

4
A. I am always challenging myself and trying new things.
B. I typically wait for others to do things and then I follow their lead.

5

A. When I de-stress, I look to my talents to help me relax.

B. When I am stressed, I feel trapped and have a hard time finding an outlet.
A. I believe that "laughter is the best medicine", and it is okay to laugh at yourself.

6

B. When I'm upset, the last thing I want to do is joke around and be silly.

7

A. Doing the right things is my first choice, even if there is uncertainty.

B. When I get even with my peers, I feel good about myself, even if it hurts their feelings.

\subsection{Data Analysis}

All the statistical analyses were performed using the Statistical Package for the Social Sciences (SPSS) for Windows, version 25.0, with a p-value less than 0.05 considered statistically significant. In this chapter, the results of the current study are presented in five sections: descriptive statistics, data distribution, correlational analysis, participants' reflection, and counselor's feedback.

\section{RESULTS}

\subsection{Mindfulness Test}

As shown in "Fig. 1", data distribution represented in the box-plot of mindfulness score showed that the median score was 20, and the average was 20.74. The interquartile range representing $50 \%$ of scores was between 18 and 24. Moreover, $25 \%$ of the participants had scores between 24 and 33. Likewise, $25 \%$ of the participants had scores between 11 and 18. Given that the lower scores indicate high self-reported mindfulness and high scores indicate low self-reported mindfulness. It can be concluded that the majority of participants had high scores, thus low self-reported mindfulness which further supports our previous results. Additionally, data is shown to be skewed and not normally distributed further indicating that data constitute higher frequency of low valued scores.

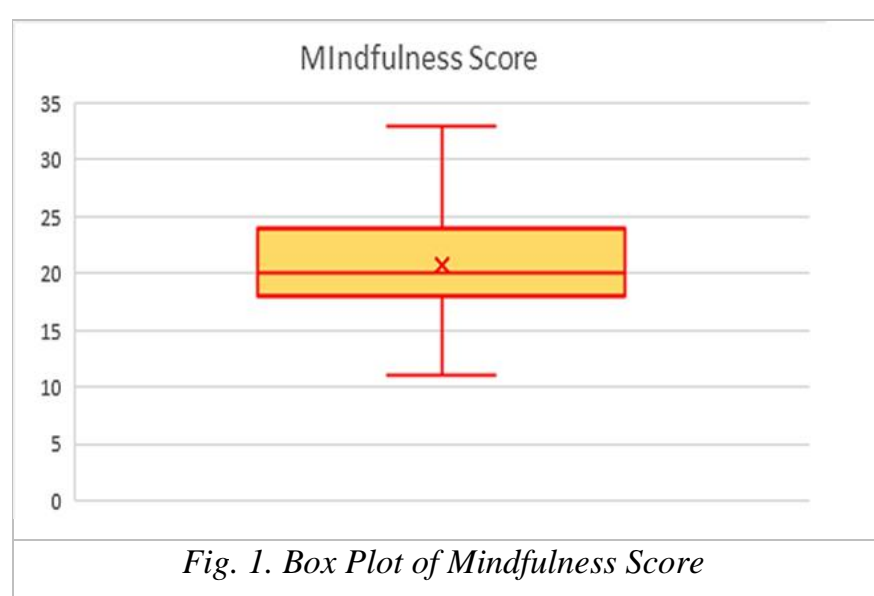

As for the distribution of the answers never true and rarely true were $18 \%$ and $20 \%$ respectively "Table $1 "$. As for those who answered sometimes true they were $22 \%$, those who answered often true they were $18 \%$ and those who answered always true they were $22 \%$ "Table 2 ".

Thus, $38 \%$ of the participants had scores lower than or equal to 2 and $40 \%$ of the participant had scores higher than or equal to 4 with $22 \%$ being in the middle "Table 2 ".

\footnotetext{
*: Have to choose Statement A or Statement B
} 
Table 2 Answers per Mindfulness Question

\begin{tabular}{lcccccc}
\hline & NT & RT & ST & OT & AT & Row Total \\
\hline I 1 & 8 & 7 & 19 & 9 & 7 & 50 \\
I 2 & 26 & 13 & 3 & 5 & 3 & 50 \\
I 3 & 14 & 12 & 13 & 6 & 5 & 50 \\
I 4 & 5 & 11 & 12 & 11 & 11 & 50 \\
I 5 & 6 & 10 & 12 & 12 & 10 & 50 \\
I 6 & 9 & 8 & 11 & 12 & 10 & 50 \\
I 7 & 9 & 10 & 9 & 12 & 10 & 50 \\
I 8 & 1 & 4 & 7 & 7 & 31 & 50 \\
I 9 & 4 & 7 & 14 & 9 & 16 & 50 \\
I 10 & 6 & 17 & 11 & 9 & 7 & 50 \\
\hline
\end{tabular}

I; item; I1: I get upset with myself for having feelings that don't make sense. I2: At school, I walk from class to class without noticing what I'm doing. I3: I keep myself busy so I don't notice my thoughts or feelings. I4: I tell myself that I shouldn't feel the way I'm feeling. I5: I push away thoughts that I don't like. I6: It's hard for me to pay attention to only one thing at a time. I7: I get upset with myself for having certain thoughts. I8: I think about things that have happened in the past instead of what's happening right now. I9: I think that some of my feelings are bad and that I shouldn't have them. I10: I stop myself from having feelings that I don't like.

T: True; N: Not; R: Rarely; S: Sometimes; O: Often; A: Always

\subsection{Self-Compassion Test}

Data distribution "Fig. 2", represented in the box-plot of self-compassion score, showed that the median and average scores were 2.9. The inter-quartile range, which represents $50 \%$ of answers, was between 2.6 and 3.1. This means that the majority of participants answered between "rarely" and "sometimes true" which reflect good standing in self-compassion. Moreover, $25 \%$ of the participants had a total self-compassion score between 2.2 and 2.6. Likewise, $25 \%$ of the participants had a score between 3.1 and 3.6. Also, data is shown to be normally distributed.

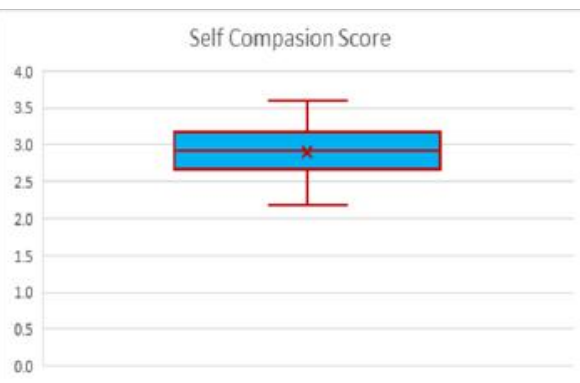

Fig. 2. Box Plot of Total Self-Compassion Score
As for the distribution of the answers within each selfcompassion category, there was no significant difference between the different categories answering percentage "Table 3". All of them followed the same pattern where around $53 \%$ of the learners answered not true and rarely true. If we add the present those who answered sometimes true to those who answered not true and rarely true we will have around $77 \%$ of the learners, leaving $24 \%$ who answered often and always true "Table 3".

Table 3 Percent Answers per Self-Compassion Categories

\begin{tabular}{lcccccc}
\hline Categories & NT & RT & ST & OT & AT & $\begin{array}{c}\text { Row } \\
\text { Total }\end{array}$ \\
\hline $\begin{array}{l}\text { Over } \\
\text { Identified }\end{array}$ & 24 & 25 & 27 & 18 & 6 & 100 \\
\hline $\begin{array}{l}\text { Self } \\
\text { Judgement }\end{array}$ & 23 & 28 & 24 & 16 & 9 & 100 \\
\hline $\begin{array}{l}\text { Self } \\
\text { Kindness }\end{array}$ & 19 & 37 & 27 & 11 & 6 & 100 \\
\hline $\begin{array}{l}\text { Mindfulness } \\
\text { Isolation }\end{array}$ & 33 & 27 & 20 & 12 & 8 & 100 \\
\hline $\begin{array}{l}\text { Common } \\
\text { Humanity }\end{array}$ & 20 & 33 & 23 & 14 & 10 & 100 \\
\hline Average & 23 & 30 & 24 & 16 & 15 & 100 \\
\hline
\end{tabular}

$\begin{array}{llllll}\text { Average } & 23 & 30 & 24 & 15 & 9\end{array}$

T: True; N: Not; R: Rarely; S: Sometimes; O: Often; A: Always

\subsection{Resilience Test}

The participants, in average, who chose $\mathrm{A}$ and thus good resilience were $64 \%$, and those who chose B and thus bad resilience were $36 \%$.

Table 4 Resilience Test Results

\begin{tabular}{cccc}
\hline Category & Choose A & Choose B & Row Total \\
\hline C 1 & 36 & 14 & 50 \\
\hline C 2 & 27 & 23 & 50 \\
\hline C 3 & 36 & 14 & 50 \\
C 4 & 38 & 12 & 50 \\
\hline C 5 & 28 & 22 & 50 \\
\hline C 6 & 33 & 17 & 50 \\
\hline C 7 & 27 & 23 & 50 \\
\hline
\end{tabular}

\subsection{Good Standing and Bad Standing of the Three Tests}

Analyzing the total scores of each test revealed that $54 \%$ of the participants enrolled in this study didn't have good standing mindfulness. Interestingly, $90 \%$ of them had good 
standing self-compassion. Likewise, $70 \%$ of them had good standing resilience "Fig. 3".

it is quite clear that the majority of participants have good standing in self-compassion and resilience, while more than half of them didn't have good standing in mindfulness "Fig. 3".

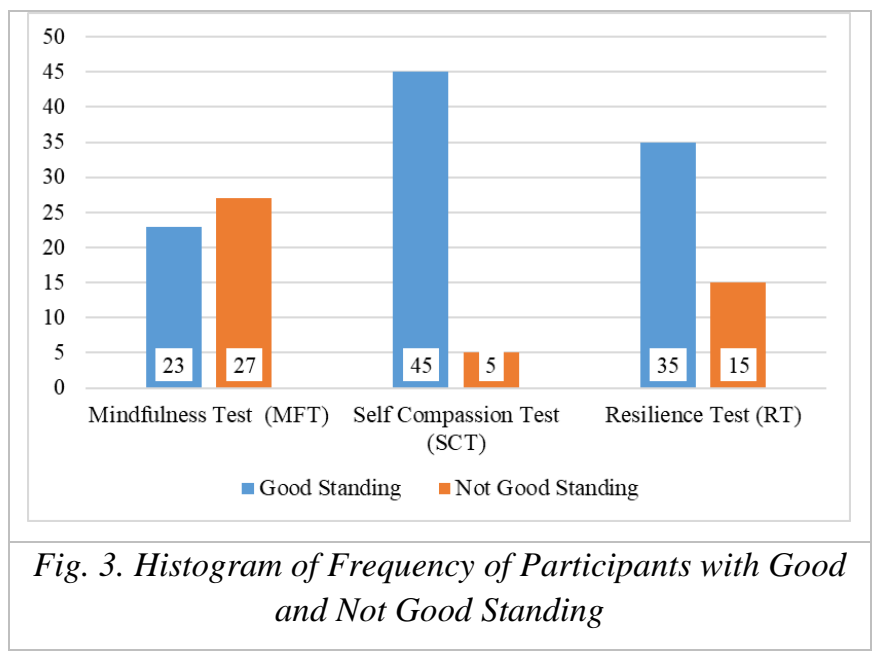

\subsection{Kendall's Tau-b Correlation Test}

Correlation between self-compassion score, mindfulness score, and resilience scores was assessed using Kendall's Tau-b Test. Kendall's $\tau$ coefficient between selfcompassion score and resilience score is insignificant although having a negative value; $\tau$ : -0.112 . Moreover, the Kendall's $\tau$ coefficient between mindfulness and resilience is insignificant although having a positive value; $\tau=0.054$. However, intriguingly a significant and positive Kendall's $\tau$ coefficient exists between self-compassion and mindfulness; $\tau$ : 0.214 ( $\mathrm{p}<0.05)$.

Table 5: Kendall's Tau-b Correlation Test between SelfCompassion Score (SCS), Mindfulness Score (MS) and Resilience Scores (RS)

\begin{tabular}{lccc} 
& SCS & MS & RS \\
\hline SCS & 1 & $0.214^{*}$ & -0.112 \\
MS & $0.214^{*}$ & 1 & 0.054 \\
RS & -0.112 & 0.054 & 1
\end{tabular}

SCS: Self Compassion Score; MS: Mindfulness Score; RS: Resilience Score: *: Significant $(\mathbf{p}<0.05)$

\section{DISCUSSION}

It is clear that the majority of participants have good standing in self-compassion and in resilience, while more than half of them didn't have good standing in mindfulness "Fig. 3". The absence of mindfulness is associated with being perpetually, unconscious and habitually preoccupied and lost in expectations and fears. As a result, they may miss out the experience of how rich each and every moment is. Instead, their minds become stuck into running by conditioned and repetitive mind habits [24] [25]. In this state, distorted thinking and over-identification rise [26] [25] [27]. Low levels of mindfulness could be associated with limited child's emotional regulation, and in turn inability to alleviate stress leading into a disordered mind state and mood [2].

In addition, good standing in self-compassion results indicate that participants have healthy coping and adaptation skills due to their ability to realize their inherent value. Besides, good standing in self-compassion means that a sense of intrinsic motivation is instilled in the participants to care for themselves [28], [29]. Selfcompassionate participants will more likely have the courage to embrace opportunities for their future personal growth, take more risks, become more curious about life, and feel secure while investigating everything offered to them. They will also recognize which actions could bring them harm, and once they take difficult decisions, they will ensure correcting their behaviors and making them better [12, 30].

As for resilience, our results showed high levels of good standing in resilience among participants which reflect their ability to properly unfold experiences and effectively cope and adapt to challenging situations. This also indicates that the vast majority of participants have the ability to "bounce back" during stressful times through utilizing coping skills that allow them recover from a given situation fairly quickly [23] [31]. Data concerning the remaining $30 \%$ of the participants who have low resilience suggest that they may lack coping skills, or their coping skills are insufficient to make them "bounce back" from stressful events in their lives [31].

Our findings showed the existence of a significant and positive correlation between self-compassion and mindfulness. This suggests that certain levels of good standing in mindfulness are required for treating oneself with compassion during challenging situations. This is in accordance with other studies which indicated that mindfulness and self-compassion play major roles in enhancing psychological adjustments and emotional wellbeing among adults [7] [32] as well as adolescents [33] [12] [34] [35] [26] [25] [27].

All in all, the studied variables: mindfulness, selfcompassion and resilience are interrelated, dependent and affect each other to a certain extent. It is possible that mindfulness is strongly correlated to self-compassion, and in turn, they contribute to resilience. Substantial evidence in the literature has indicated that mindfulness and self- 
compassion improve cognitive performance and increase resilience [36] [35]. Our results are consistent with those obtained by Greco et al. (2011), whereby the correlation between mindfulness and self-compassion utilizing the CAMM scale among 5th to 10 th graders revealed significant correlation between mindfulness and selfcompassion highlighting their importance in enhancing quality of life and overcoming problems [37].

\section{CONCLUSION}

The findings of the current study and the extensive literature reinforce the important role of mindfulness, selfcompassion and resilience among children. This study highlights the impact of mindfulness and self-compassion on promoting and building resilience. It also shows support for the development of programs, such as MSC program, for school students that target promoting resilience through mindfulness and self-compassion to enhance their ability to effectively manage complex challenges and adversities. However, more research is warranted to understand more about mindfulness, selfcompassion and resilience in the Lebanese society. More studies should be conducted regarding finding ways and programs to increase their levels among Lebanese students. Finally, building resilience is crucial for stabilizing the mental health of individuals and contributing it to their normal growth which in turn builds a great society that can face all adversities.

\section{REFERENCES}

[1] Neff, K. and C. Germer, The transformative effects of mindful self-compassion. Mindful. Retrieved from, 2019.

[2] Remmers, C., S. Topolinski, and S.L. Koole, Why being mindful may have more benefits than you realize: Mindfulness improves both explicit and implicit mood regulation. Mindfulness, 2016. 7(4): p. 829-837.

[3] Ortiz, R. and E.M. Sibinga, The role of mindfulness in reducing the adverse effects of childhood stress and trauma. Children, 2017. 4(3): p. 16.

[4] Seppälä, E.M., et al., Promoting mental health and psychological thriving in university students: a randomized controlled trial of three well-being interventions. Frontiers in psychiatry, 2020. 11: p. 590.

[5] Garrison, J.L., A Self-Compassion and Mindfulness Program for Preschoolers. 2017, San Diego State University.

[6] Lawlor, M.S., Mindfulness and social emotional learning (SEL): A conceptual framework, in Handbook of mindfulness in education. 2016, Springer. p. 65-80.

[7] Khoury, B., et al., Mindfulness-based therapy: a comprehensive meta-analysis. Clinical psychology review, 2013. 33(6): p. 763-771.
[8] Maalouf, F.T., et al., Psychiatric disorders among adolescents from Lebanon: prevalence, correlates, and treatment gap. Social psychiatry and psychiatric epidemiology, 2016. 51(8): p. 1105-1116.

[9] Khamis, V., Impact of war, religiosity and ideology on PTSD and psychiatric disorders in adolescents from Gaza Strip and South Lebanon. Social Science \& Medicine, 2012. 74(12): p. 2005-2011.

[10] El Hassan, K., SCHoolIng oF young ADolESCEntS In 1EBAnon. Handbook on International Studies in Education, 2010: p. 77.

[11] Kabat-Zinn, J., Foreword: Seeds of a necessary global renaissance in the making: the refining of psychology's understanding of the nature of mind, self, and embodiment through the lens of mindfulness and its origins at a key inflection point for the species. Curr Opin Psychol, 2019. 28: p. xi-xvii.

[12] Neff, K.D., Self-compassion, self-esteem, and well-being. Social and personality psychology compass, 2011. 5(1): p. 1-12.

[13] Mayzell, G. and P.S. Normand, The Importance of Measuring Burnout, in The Resilient Healthcare Organization. 2020, Productivity Press. p. 39-52.

[14] Neely, M.E., et al., Self-kindness when facing stress: The role of self-compassion, goal regulation, and support in college students' well-being. Motivation and Emotion, 2009. 33(1): p. 88-97.

[15] Goldstein, S., Encyclopedia of child behavior and development. Vol. 2. 2010: Springer Science \& Business Media.

[16] Rose, A.V. and K.A. Rimes, Self-criticism self-report measures: Systematic review. Psychology and Psychotherapy: Theory, Research and Practice, 2018. 91(4): p. $450-489$.

[17] Gaita, R., A common humanity: Thinking about love and truth and justice. 2013: Routledge.

[18] Schutte, N.S., et al., Characteristic emotional intelligence and emotional well-being. Cognition \& Emotion, 2002. 16(6): p. 769-785.

[19] Leech, N.L. and A.J. Onwuegbuzie, Qualitative data analysis: A compendium of techniques and a framework for selection for school psychology research and beyond. School psychology quarterly, 2008. 23(4): p. 587.

[20] Ruggiano, N. and T.E. Perry, Conducting secondary analysis of qualitative data: Should we, can we, and how? Qualitative Social Work, 2019. 18(1): p. 81-97.

[21] Kuby, A.K., N. McLean, and K. Allen, Validation of the Child and Adolescent Mindfulness Measure (CAMM) with non-clinical adolescents. Mindfulness, 2015. 6(6): p. 14481455 .

[22] 22. Neff, K.D., The development and validation of a scale to measure self-compassion. Self and identity, 2003. 2(3): p. 223-250.

[23] Siebert, A., The resiliency advantage: Master change, thrive under pressure, and bounce back from setbacks. 2005: Berrett-Koehler Publishers. 
[24] Baer, R.A., Mindfulness training as a clinical intervention: a conceptual and empirical review. Clinical psychology: Science and practice, 2003. 10(2): p. 125.

[25] Kabat-Zinn, J., Coming to our senses: Healing ourselves and the world through mindfulness. 2005: Hachette UK.

[26] Bishop, S.R., et al., Mindfulness: a proposed operational definition. Clinical psychology: Science and practice, 2004 11(3): p. 230.

[27] Siegel, R.D., C.K. Germer, and A. Olendzki, Mindfulness: What is it? Where did it come from?, in Clinical handbook of mindfulness. 2009, Springer. p. 17-35.

[28] Barnard, L.K. and J.F. Curry, Self-compassion: Conceptualizations, correlates, \& interventions. Review of general psychology, 2011. 15(4): p. 289-303.

[29] Neff, K.D. and C.K. Germer, A pilot study and randomized controlled trial of the mindful self-compassion program. Journal of clinical psychology, 2013. 69(1): p. 28-44.

[30] Neff, K., S.-C.I.M. Leary, and R. Hoyle, Individual Differences in Social Behavior (pp. 561-573). New York: Guilford Press. 2009.

[31] Goldstein, S. and R.B. Brooks, Resilience in children. New York: Springer. Gooding, HC, Milliren, CE, Austin, SB, Sheridan, MA, \& McLaughlin, KA (2016). Child abuse, resting blood pressure, and blood pressure reactivity to psychological stress. Journal of Pediatric Psychology, 2005. 41: p. 5-12.

[32] 32. MacBeth, A. and A. Gumley, Exploring compassion: A meta-analysis of the association between self-compassion and psychopathology. Clinical psychology review, 2012. 32(6): p. 545-552.

[33] Bluth, K. and T.A. Eisenlohr-Moul, Response to a mindful self-compassion intervention in teens: A within-person association of mindfulness, self-compassion, and emotional well-being outcomes. Journal of Adolescence, 2017. 57: p. 108-118.

[34] Zessin, U., O. Dickhäuser, and S. Garbade, The relationship between self-compassion and well-being: A meta-analysis. Applied Psychology: Health and Well-Being, 2015. 7(3): p. 340-364.

[35] Zoogman, S., et al., Mindfulness interventions with youth: A meta-analysis. Mindfulness, 2015. 6(2): p. 290-302.

[36] Zenner, C., S. Herrnleben-Kurz, and H. Walach, Mindfulness-based interventions in schools - a systematic review and meta-analysis. Frontiers in psychology, 2014. 5: p. 603.

[37] Greco, L.A., R.A. Baer, and G.T. Smith, Assessing mindfulness in children and adolescents: development and validation of the Child and Adolescent Mindfulness Measure (CAMM). Psychological assessment, 2011. 23(3): p. 606. 